\title{
Keanekaragaman Jenis, Tutupan Lamun, dan Kualitas Air di Perairan Teluk Ambon
}

\author{
Marsya J. Rugebregt ${ }^{1}$, Caleb Matuanakotta ${ }^{1}$, dan Syafrizal ${ }^{1}$ \\ 1Pusat Penelitian Laut Dalam - LIPI; e-mail: marsya.rugebregt@gmail.com
}

\begin{abstract}
ABSTRAK
Ekosistem lamun memiliki fungsi ekologi sebagai habitat, tempat pemijahan, pengasuhan, pembesaran, dan mencari makanan dari berbagai biota. Berkembangnya kegiatan manusia di wilayah pesisir khususnya di perairan Teluk Ambon seperti pariwisata, pemukiman, dan aktivitas lainnya berpengaruh terhadap ekosistem lamun. Tujuan penelitian ini untuk mengetahui keanekaragaman jenis dan persentase tutupan, serta kualitas air di ekosistem lamun Teluk Ambon. Penelitian dilakukan pada bulan September 2019 di Teluk Ambon pada tujuh stasiun yaitu Tanjung Tiram, Halong, Galala, Lateri, Passo, Waiheru, dan Tawiri. Data diperoleh menggunakan teknik transek dengan mengadopsi protocol dari UNESCO pada ekositem lamun yang kontinu atau koleksi bebas pada vegetasi lamun. Parameter kualitas air yang diukur meliputi parameter fisika (suhu dan salinitas) dan parameter kimia (pH, DO, nitrat, silikat dan fosfat. Suhu, salinitas, pH, dan Do diukur secara in situ dengan menggunakan Water Quality Checker WTW 3430 Set F. Sampel air dianalisa pada laboratorium Pusat Penelitian Laut Dalam LIPI Ambon menggunakan metode spektrofotometri. Hasil yang diperoleh terdapat enam jenis lamun yang ditemukan di Teluk Ambon yaitu Enhalus acroides, Thalassia hemprichii, Halophila ovalis, Halophila minor, Cymonocea rotundata, dan Halodule pinifolia. Persentase tutupan lamun stasiun Galala : E. acroides $(34,41 \%)$, T. hemprichii $(28,37 \%)$, H. ovalis $(1,40 \%)$ dan H. pinifolia (35.81\%); Halong : E. acroides $(29,42 \%)$, T. hemprichii $(7,95 \%)$, H. ovalis $(1,77 \%)$, C. rotundata $(10.58 \%)$ dan H. pinifolia (35.81\%); Tj. Tiram : E. acroides (41.51\%), T. hemprichii $(52,72 \%)$, H. ovalis $(0,61 \%)$ dan H. pinifolia (5.16\%); Lateri : E. acroides (76.25\%) dan T. hemprichii (52,72\%); Passo : H. minor (100\%); Waiheru : E. acroides (100\%); Tawiri H. ovalis $(46,45 \%)$ dan H. pinifolia (53.55\%). Suhu perairan lebih rendah dari suhu optimum. Salinitas perairan dan DO masih dalam bakumutu yang diperolehkan. Berdasarkan nilai $\mathrm{pH}$ maka perairan Teluk Ambon tergolong perairan tidak produktif. Kadar fosfat dan nitrat lebih tinggi dari baku mutu berdasarkan KMNLH 2004.
\end{abstract}

Kata kunci: Lamun, Keanekaragaman, Tutupan lamun, Kualitas air, Teluk Ambon

\begin{abstract}
The seagrass ecosystem has ecological function as a habitat, spawning, nurturing, growing, and foraging for food from various biota. Developing activities in the coastal area in the Ambon Bay waters, such as activities, settlements, and other activities that affect the seagrass ecosystem. The research objective was to determine the diversity of types and proportions of cover, and water quality in the Ambon Bay seagrass ecosystem. The research was conducted in September 2019 in Ambon Bay at seven stations namely Tanjung Tiram, Halong, Galala, Lateri, Passo, Waiheru, and Tawiri. Data were obtained using the transect technique with UNESCO protocol on continuous seagrass ecosystem or free collection of seagrass vegetation. Water quality parameters measured include physical parameters (temperature and salinity) and chemical parameters (pH, DO, nitrates, silicates, and phosphates. Temperature, salinity, pH, and measured in situ using Water Quality Checker WTW 3430 Set F. Air analysis The results obtained were six types of seagrass found in Ambon Bay, namely Enhalus acroides, Thalassia hemprichii, Halophila ovalis, Halophila minor, Cymonocea rotundata, and Halodule pinifolia. Percentage of seagrass station coverage of Galala : E. acroides $(34,41 \%)$, T. hemprichii $(28,37 \%), H$. ovalis $(1,40 \%)$ and H. pinifolia $(35,81 \%)$; Halong: E. acroides $(29,42$ $\%)$ ), T. hemprichii $(7,95 \%), H$. ovalis $(1,77 \%)$, C. rotundata $(10,58 \%)$, and H. pinifolia $(35,81 \%)$; Tj. Oysters: E. acroides $(41,51 \%)$, T. hemprichii $(52,72 \%), H$. ovalis $(0,61 \%)$ and $H$. pinifolia $(5,16 \%)$; Lateri: E. acroides $(76,25 \%)$ and T. hemprichii (52,72\%); Passo: H. minor (100\%); Waiheru: E. acroides (100\%); Tawiri; H. ovalis $(46,45 \%)$ and H. pinifolia $(53,55 \%)$. The water temperature is lower than the optimal temperature. The salinity of the waters and DO are still in the quality obtained. Based on the $\mathrm{pH}$ value, the waters of Ambon Bay are classified as non-productive waters. Phosphate and nitrate levels were higher than the quality standard based on KMNLH 2004.
\end{abstract}

Keywords: Seagrass, Diversity, Seagrass cover, Water quality, Ambon bay

Citation: Rugebregt, M.J., Matuanakotta, C., dan Syafrizal (2020). Keanekaragaman jenis, Tutupan Lamun, dan Kualitas Air di Teluk Ambon. Jurnal Ilmu Lingkungan, 18(3), 589-594, doi:10.14710/jil.18.3.589-594 


\section{Pendahuluan}

Ekosistem lamun merupakan salah satu ekosistem penting di laut, disamping terumbu karang dan mangrove sebagai pendukung kehidupan biota. Ekosistem lamun memiliki fungsi ekologi diantaranya adalah sebagai habitat (tempat hidup), tempat pemijahan (spawning ground), pengasuhan (nursery ground), pembesaran (rearing ground), dan mencari makanan (feeding ground) dari berbagai biota. Selain itu sebagai produsen primer, penangkap sedimen, serta pendaur zat hara (Kordi, 2011).

Ekosistem lamun dibatasi oleh beberapa faktor lingkungan yaitu suhu, cahaya, salinitas, kedalaman, substrat dasar, nutrien dan pergerakan air laut (ombak, arus, pasang surut). Nutrien yang berpengaruh pada pertumbuhan lamun adalah nitrogen $(\mathrm{N})$ dan fosfor $(\mathrm{P})$. Nitrogen dan fosfor yang terukur di Teluk Ambon masih berada dalam jumlah yang cukup untuk pertumbuhan lamun. Pengkayaan nutrien (eutrofikasi) dapat memicu pertumbuhan algae epifitik pada daun lamun maupun algae di kolom air. Kedua tipe blooming algae tersebut mengurangi jumlah cahaya yang mencapai lamun. Hal ini mengurangi efektifitas fotosintesis sehingga menekan produktivitas lamun dan menyebabkan penurunan komunitas lamun di seluruh dunia (Papathanasiou et al. 2015; Waycott et al. 2007; Christianen et al., 2011).

Faktor lingkungan tersebut juga mempengaruhi kelimpahan dan kerapatan lamun pada suatu daerah, sehingga jumlah dan kelimpahan lamun berbeda-beda pada setiap daerah ekosistem lamun. Teluk Ambon terbagi atas dua yaitu Teluk Ambon bagian dalam (TAD) dan Teluk Ambon bagian luar (TAL). Berkembangnya kegiatan manusia di wilayah pesisir khususnya di perairan Teluk Ambon seperti kegiatan pariwisata, pemukiman, dan aktivitas lainnya memungkinkan adanya pengaruh terhadap ekosistem lamun, sehingga diduga mengalami perubahan fisik, kelimpahan, maupun sebarannya.

Menurut Kiswara (2004), hilangnya lamun secara luas telah terjadi di berbagai tempat di belahan dunia sebagai akibat langsung dari kegiatan manusia termasuk kerusakan secara mekanis (pengerukan), pengaruh pembangunan konstruksi pesisir. Oleh karena itu perlu dilakukan penelitian mengenai keberadaan dan kelimpahan lamun. Monitoring kondisi ekosistem lamun Teluk Ambon dilakukan setiap tahunnya untukmengetahui tutupan lamun di kawasan ini.

Tujuan dari penelitian yang dilaksanakan di Teluk Ambon ini untuk mengetahui kondisi terkini dari keanekaragaman jenis dan persentase tutupan lamun akibat dari berbagai tekanan terhadap ekosistem tersebut serta kondisi kualitas air di ekosistem lamun Teluk Ambon.

\section{Metode Penelitian}

Penelitian ini dilakukan pada bulan September 2019 di Teluk Ambon dengan 7 (tujuh) stasiun penelitian yang merupakan stasiun monitoring lamun (Gambar 1). Data utama yang diamati di lapangan adalah keberadaan lamun pada 7 (tujuh) stasiun (Tj. 590
Tiram, Halong, Galala, Lateri, Passo, Waiheru, Tawiri). Stasiun-stasiun tersebut dipilih karena merupakan stasiun monitoring Teluk Ambon yang selama ini digunakan oleh LIPI untuk memonitoring perubahan kondisi ekosistem Lamun di Teluk Ambon. Teluk Ambon sendiri terbagi atas dua bagian yaitu Teluk Ambon Luar (TAL) dan Teluk Ambon Dalam (TAD). Teluk Ambon Luar (TAL) merupakan bagian Teluk Ambon yang berhubungan langsung dengan Laut Banda. Teluk Ambon Dalam merupakan bagian Teluk Ambon yang kondisinya semi tertutup.

Data diperoleh menggunakan teknik transek dengan mengadopsi protocol dari UNESCO (English et al., 1994) (Gambar 2) pada ekosistem lamun yang kontinu atau koleksi bebas pada vegetasi lamun yang sepenggal-sepenggal (patchy). Transek dipasang tegak lurus garis pantai, dari batas mulai lamun ditemukan hingga lamun tidak teramati lagi. Setiap 10 meter di garis transek diletakkan bingkai kuadrat dengan ukuran $50 \times 50 \mathrm{~cm}$. Persentase tutupan lamun dalam bingkai dan persentase tutupan per jenis lamun di dalam kuadrat diamati dan dicatat

Identifikasi jenis lamun menggunakan referensi The Sea-grasses of the World (den Hartog, 1970), Seagrass from the Philippines (Menez, et al., 1983), Pedoman Inventarisasi Lamun (Azkab, 1999), dan Seagrasses: Biology, Ecology and Conservation (den Hartog \& Kuo, 2006).

Parameter kualitas air yang diukur meliputi parameter fisika (suhu dan salinitas) dan parameter kimia (pH, DO, nitrat, silikat dan fosfat. Suhu, salinitas, $\mathrm{pH}$, dan Do diukur secara in situ dengan menggunakan Water Quality Checker (WQC) WTW 3430 Set F. Sampel air dibawa ke laboratorium kimia Pusat Penelitian Laut Dalam LIPI Ambon untuk analisa nitrat, silikat dan fosfat dengan menggunakan metode spektrofotometri.

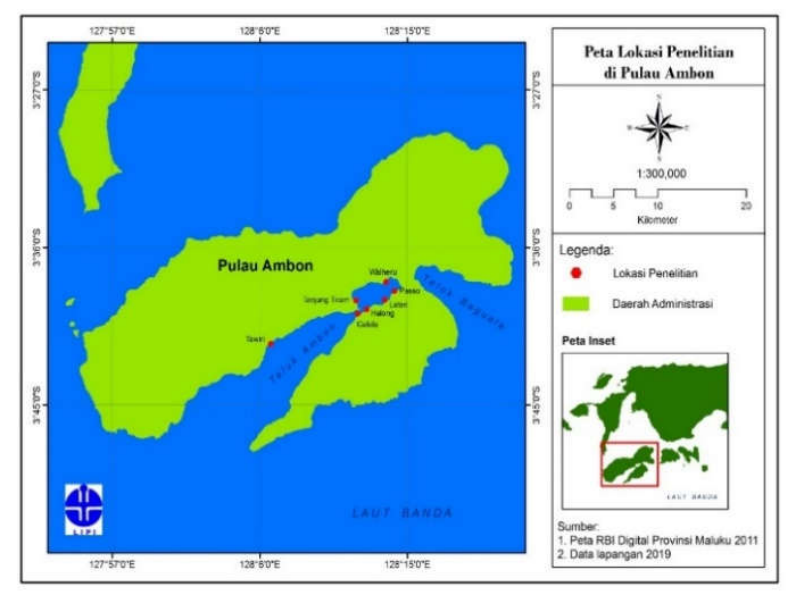

Gambar 1. Lokasi Penelitian Ekosistem Lamun Teluk Ambon 


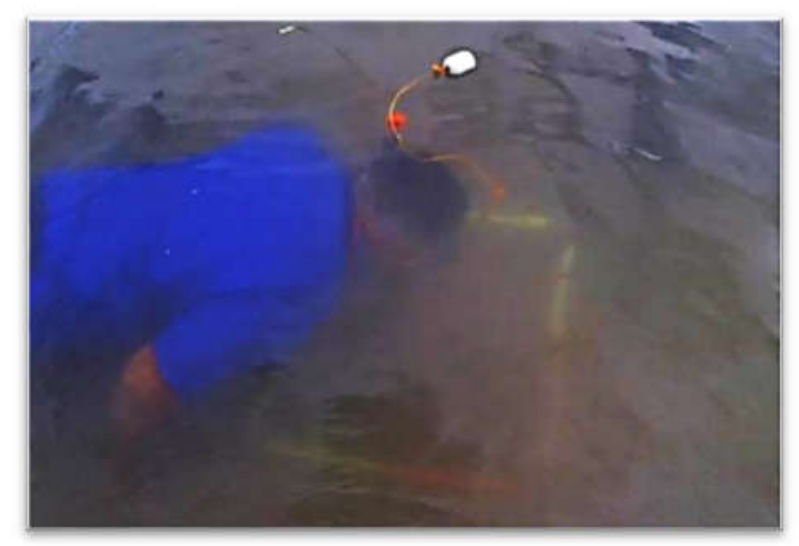

Gambar 2. Teknik Pengambilan Data dengan Metode Transek

\section{Hasil dan Pembahasan}

Pada penelitian Monitoring Teluk Ambon ini diperoleh hasil bahwa stasiun Halong memiliki keanekaragaman jenis lamun yang lebih baik dari stasiun lainnya. Hal ini disebabkan stasiun Halong berada pada daerah militer (Angkatan Laut) sehingga tidak terjadi aktivitas manusia yang mengganggu ekosistem tersebut. Enhalus acoroides merupakan jenis lamun yang paling sering ditemui di perairan teluk Ambon. Daerah Passo didominasi Halophila minor karena memiliki substrat pasir halus yang sangat cocok untuk pertumbuhan lamun jenis ini. Kehadiran lamun dan persentasi tutupan lamun disajikan pada Tabel 1.

Tabel 1. Kehadiran Lamun Teluk Ambon Tahun 2019

\begin{tabular}{|c|c|c|c|c|c|c|c|}
\hline \multirow{2}{*}{ Jenis } & \multicolumn{7}{|c|}{ Stasiun } \\
\hline & GALALA & HALONG & TJ, TIRAM & LATERI & PASSO & WAIHERU & TAWIRI \\
\hline HYDROCHARITACEAE & & & & & & & \\
\hline Enhalus acoroides & + & + & + & + & - & + & - \\
\hline Thalasia hemprichii & + & + & + & + & - & - & - \\
\hline Halophila ovalis & + & + & + & - & - & - & + \\
\hline $\begin{array}{r}\text { Halophila minor } \\
\text { CYMODOCEAE }\end{array}$ & - & - & - & - & + & - & - \\
\hline Cymodocea rotundata & - & + & - & - & - & - & - \\
\hline Halodule pinifolia & + & + & + & - & - & - & + \\
\hline
\end{tabular}

Setiap stasiun penelitian memiliki kondisi substrat yang berbeda sehingga mempengaruhi jenis lamun, namun akibat berbagai kegiatan manusia juga turut mempengaruhi keberadaan dan persentasi tutupan lamun.

Stasiun penelitian di Galala terletak di antara Teluk Ambon Luar dan Teluk Ambon Dalam, dekat dengan dermaga perahu penyeberang dengan karakteristik yang teramati selama penelitian di lokasi ini antara lain kondisi perairan sedikit berombak dan keruh dengan substrat dominan berupa pasir. Tidak ada terumbu karang maupun mangrove, namun terdapat padang lamun yang komposisi jenisnya terdiri dari Enhalus acoroides, Thalassia hemprichii, Halophila ovalis, dan Halodule pinifolia. Jumlah jenis ini lebih banyak dari data tahun 2017 yang hanya menjumpai jenis E. acoroides dan $T$. hempricii, dengan jenis yang dominan adalah Halodule pinifolia.

Stasiun penelitian di Halong terletak di Teluk Ambon Dalam, pada pantai berpasir dengan karakteristik yang teramati selama penelitian di lokasi ini antara lain kondisi perairan tenang dan sedikit keruh dengan substrat dominan berupa pasir. Padang lamun di stasiun Halong ini memiliki panjang dari pantai ke arah laut sekitar 50 meter, dengan batas padang lamun pada terumbu karang. Komposisi jenis lamun terdiri dari Halodule pinifolia, Enhalus acoroides, Thalassia hemprichii, Cymodocea rotundata dan Halophila ovalis. Jumlah jenis yang dijumpai pada penelitian saat ini sama dengan data tahun 2008 dan 2011 sebanyak lima jenis (Irawan, 2011; Irawan \& Nganro, 2016).

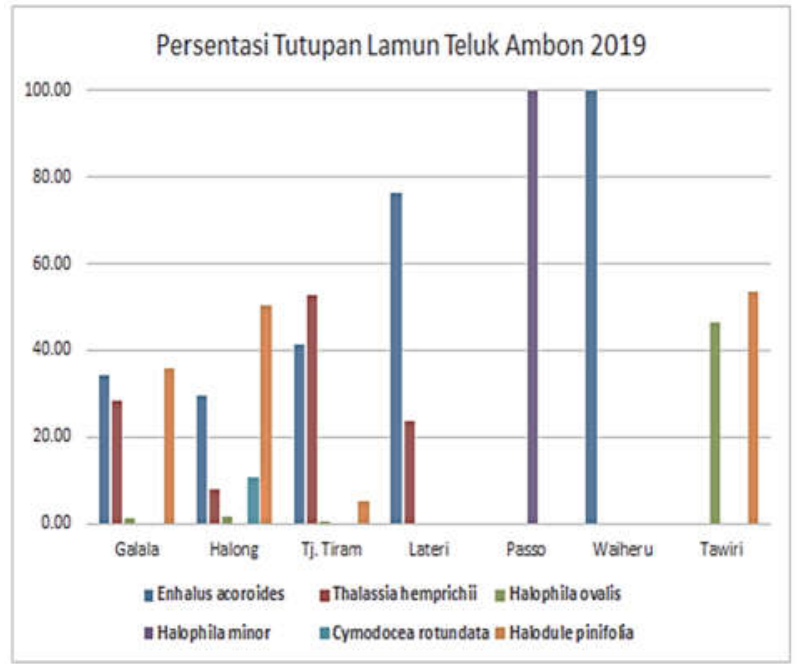

Gambar 3. Jenis dan Tutupan Lamun Teluk Ambon, 2019

Stasiun penelitian di Tanjung Tiram terletak di Teluk Ambon bagian dalam, dekat dengan dermaga vegetasi mangrove, dengan karakteristik yang teramati selama penelitian di lokasi ini antara lain kondisi perairan tenang dan cukup jernih dengan substrat dominan berupa pasir. Padang lamun di lokasi ini memiliki panjang dari pantai ke arah laut sekitar 130 meter, dengan batas padang lamun pada terumbu karang. Komposisi jenis lamun terdiri dari Halodule pinifolia, Enhalus acoroides, Thalassia hemprichii dan Halophila ovalis. Jumlah jenis yang dijumpai pada penelitian kali ini lebih rendah dari data tahun 2008 dan 2011 sebanyak lima jenis (Irawan, 2011; Irawan \& Nganro, 2016). Jenis yang tidak dijumpai pada tahun 2017 adalah Halophila ovalis dan H. minor. Sedangkan pada tahun 2019 tidak dijumpai H. minor. 
Stasiun penelitian di Lateri terletak di Teluk Ambon Dalam, pada pantai berpasir dan pecahan batu dan dekat dengan dermaga Badan Keamanan Laut, dengan karakteristik yang teramati selama penelitian di lokasi ini antara lain kondisi perairan tenang dan sedikit keruh dengan substrat dominan berupa pasir dan pecahan batu. Padang lamun di lokasi ini memiliki panjang dari pantai ke arah laut sekitar 30 meter dengan komposisi jenis lamun terdiri dari Enhalus acoroides dan Thalassia hemprichii. Tidak ada perubahan komposisi jenis berdasarkan pada data tahun 2017.

Stasiun penelitian di Passo terletak di ujung Teluk Ambon bagian dalam, pada pantai berpasir dekat dengan vegetasi mangrove, dengan karakteristik yang teramati selama penelitian di lokasi ini antara lain kondisi perairan tenang dan keruh dengan substrat dominan berupa pasir. Padang lamun di lokasi ini memiliki panjang dari pantai ke arah laut sekitar 70 meter, dengan komposisi jenis lamun hanya terdiri dari Halophila minor. Tidak ada perubahan komposisi jenis berdasarkan pada data tahun 2008 dan 2011 (Irawan, 2011; Irawan \& Nganro, 2016) dan tahun 2017.

Stasiun penelitian di Waiheru terletak di Teluk Ambon bagian dalam, pada pantai berpasir dekat dengan vegetasi mangrove, dengan karakteristik yang teramati selama penelitian di lokasi ini antara lain kondisi perairan sedikit berombak dan keruh dengan substrat dominan berupa pasir berlumpur. Padang lamun di lokasi ini memiliki panjang dari pantai ke arah laut sekitar 90 meter, dengan komposisi jenis lamun hanya terdiri dari Enhalus acoroides. Tidak ada perubahan komposisi jenis berdasarkan pada data tahun 2008, 2011, dan 2017 (Irawan, 2011; Irawan \& Nganro, 2016).

Stasiun penelitian di Tawiri terletak di Teluk Ambon Luar, pada pantai pasir berbatu dekat dengan beberapa pohon mangrove, dengan karakteristik yang teramati selama penelitian di lokasi ini antara lain kondisi perairan tenang dan sedikit keruh dengan substrat dominan berupa pasir dan batu. Padang lamun di lokasi ini memiliki panjang dari pantai ke arah laut sekitar 20 meter ditambah beberapa penggalan tumbuhan lamun yang terpisah dengan vegetasi yang kontinu. Komposisi jenis lamun terdiri dari dua jenis yaitu Halodule pinifolia dan Halophila ovalis.

Beberapa stasiun yang memiliki padang lamun mengalami perubahan baik di komposisi jenis lamun maupun tutupannya. Hal ini disebabkan pengaruh kegiatan manusia maupun faktor alam seperti arus dan gelombang. Stasiun Galala sangat mendapat tekanan disebabkan oleh pembangunan Jembatan Merah Putih yang berpengaruh terhadap rusaknya ekosistem lamun karena penggalian, sedimentasi, dan perubahan arus yang membuat ekosistem lamun rusak dan penutupan lamun berkurang. Stasiun Tanjung Tiram mengalami kerusakan karena kegiatan 'bameti' yaitu kegiatan gleaning shellfish (memungut kerang-kerangan) dan udang saat air laut lagi surut "meti" dan pada saat bulan gelap dan kegiatan ini merusak lamun karena terinjak dan dicabuti. Selain itu stasiun Tanjung Tiram juga digunakan nelayan untuk melabuhkan kapal dan perahu. Jangkar kapal dapat merusak ekosistem lamun. Stasiun Halong perlu diteliti kembali di luar transek permanen untuk melihat apakah jenis lamun yang kali ini tidak dijumpai masih bisa ditemui di luar transek permanen. Bisa juga dilakukan penelitian lain secara monitoring sebaran lamun pada area tersebut untuk melihat pergeseran sebaran lamun pada periode tertentu. Untuk lokasi yang tutupannya menurun seperti Tanjung Tiram, Passo dan Waiheru perlu mendapat perhatian lebih karena berimbas pada menurunnya juga kemampuan vegetasi dalam menyokong ekosistem. Upaya yang bisa dilakukan adalah melakukan kajian apakah ada kegiatan yang berpotensi merusak lamun saat ini di sekitar tiga lokasi tersebut. Selain itu, bisa juga dilakukan upaya rehabilitasi lokasi tersebut melalui kegiatan transplantasi untuk meningkatkan kembali kerapatan lamun yang juga akan meningkatkan tutupannya.

Yang menjadi syarat utama habitat dari lamun adalah perairan yang dangkal, memiliki substrat yang lunak dan perairan yang cerah (Tuapattinaya, 2014). Syarat lainnya adalah adanya sirkulasi air yang membawa bahan nutrient dan substrat serta membawa pergi sisa metabolisme. Dari hasil Analisa maka diperoleh kualitas air setiap stasiun penelitian yang disajikan dalam Tabel 2.

Tabel 2. Kualitas Perairan Ekosistem Lamun Teluk Ambon, 2019

\begin{tabular}{|c|c|c|c|c|c|c|}
\hline \multirow[t]{2}{*}{ Stasiun } & \multicolumn{5}{|c|}{ Stasiun } & \multirow[b]{2}{*}{ Nitrat $(\mathrm{mg} / \mathrm{L})$} \\
\hline & $\mathrm{pH}$ & $\mathrm{DO}(\mathrm{mg} / \mathrm{L})$ & Suhu $\left({ }^{\circ} \mathrm{C}\right)$ & Salinitas (\%) & Fosfat (mg/L) & \\
\hline Galala & 8,72 & 6,91 & 25,5 & 26 & 0,1607 & 0,0058 \\
\hline Halong & 8,7 & 6,87 & 26,1 & 31 & 0,1607 & 0,0160 \\
\hline Tj. Tiram & 8,89 & 6,09 & 26,7 & 21 & 0,2052 & 0,0067 \\
\hline Lateri & 8,7 & 6,91 & 26,6 & 34 & 0,2140 & 0,0000 \\
\hline Passo & 8,6 & 7,02 & 26,6 & 30 & 0,1785 & 0,0049 \\
\hline Waiheru & 8,6 & 7,11 & 26,3 & 31 & 0,1785 & 0,0000 \\
\hline Tawiri & 8,64 & 7,21 & 25,1 & 30 & 0,1607 & 0,0000 \\
\hline
\end{tabular}

Suhu air yang berbeda pada masing-masing stasiun diduga disebabkan adanya perbedaan kedalaman perairan dan kerapatan vegetasi lamun. Perairan yang dangkal akan menerima intensitas cahaya matahari lebih tinggi daripada perairan yang lebih dalam sehingga suhu di perairan yang dangkal akan lebih tinggi daripada di perairan yang lebih dalam. Lamun yang hidup di daerah tropis dapat tumbuh optimal pada suhu $28-30{ }^{\circ} \mathrm{C}$. Hal ini 
berkaitan dengan kemampuan proses fotosintesis (Tuwo, 2011).

Salinitas yang baik bagi kehidupan lamun berada pada kisaran 10 - 40\%o. Menurut Short dan Coles (2003), salinitas yang terlalu tinggi dapat menjadi faktor pembatas bagi penyebaran lamun, menghambat perkecambahan biji lamun, menimbulkan stress osmotik dan menurunkan daya tahan terhadap penyakit. Kondisi salinitas di stasiun pengamatan menunjukkan suatu rentang yang baik bagi lamun untuk tumbuh dan berkembang secara optimal.

pH air merupakan salah satu faktor yang dapat mempengaruhi produktifitas perairan. Kisaran derajat keasaman yang ditemukan dari seluruh stasiun merupakan kisaran yang masih normal untuk perairan tropis. Kaswadji (1997) dalam Nur (2004) mengatakan bahwa suatu perairan dengan $\mathrm{pH}$ 5,5 6,5 dan $\mathrm{pH}$ yang lebih dari 8,5 merupakan perairan yang tidak produktif, perairan dengan $\mathrm{pH}$ 6,5-7,5 termasuk dalam perairan yang masih produktif dan perairan dengan $\mathrm{pH}$ antara 7,5 - 8,5 mempunyai tingkat produktifitas yang tinggi.

Nilai kandungan oksigen terlarut (DO) perairan ekosistem lamun selalu berfluktuasi. Berfluktuasinya kandungan oksigen terlarut di suatu perairan diduga disebabkan pemakaian oksigen terlarut oleh lamun untuk respirasi akar dan rimpang, respirasi biota air dan pemakaian oleh bakteri nitrifikasi dalam proses siklus nitrogen di ekosistem lamun (Felisberto et al. 2015). Nilai kandungan oksigen terlarut (DO) yang terukur di Teluk Ambon masih berada dalam jumlah yang cukup untuk pertumbuhan lamun.

Kadar fosfat dan nitrat berdasarkan Kep.MNLH Nomor 51 Tahun 2004 standar baku mutu untuk biota laut adalah $0,015 \mathrm{mg} / \mathrm{l}$ dan $0,008 \mathrm{mg} / \mathrm{l}$. Tingginya kandungan nitrat dan fosfat di perairan Teluk Ambon sangat erat hubungannya dengan beberapa faktor. Menurut Amelia et al (2014), sumber utama nitrat di perairan berasal dari limbah rumah tangga dan limbah pertanian seperti kotoran hewan dan manusia. Fosfat memiliki sumber utama dari proses dekomposisi bahan organik didalam sedimen. Sumber fosfat yang lain pada perairan juga dapat berasal dari pelapukan batuan, limbah industri, domestik dan pertanian (Patty et al., 2015). Perairan Teluk Ambon dipengaruhi oleh aktivitas manusia yang tinggi, sehingga memiliki banyak sumber utama nitrat dan fosfat di dalamnya.

\section{Kesimpulan}

Dari hasil penelitian ditemukan enam jenis lamun di Teluk Ambon yaitu Enhalus acoroides, Thalassia hemprichii, Halophila ovalis, Halophila minor, Cymodocea rotundata dan Halodule pinifolia. Jumlah jenis yang dijumpai pada penelitian kali ini lebih rendah dari data tahun 2008 dan 2011 sebanyak lima jenis.

Persentase tutupan lamun pada setiap stasiun penelitian sebagai berikut; Galala : E. acroides $(34,41 \%)$, T. hemprichii $(28,37 \%), H$. ovalis $(1,40 \%)$ dan $H$. pinifolia (35.81\%). Halong : E. acroides $(29,42 \%)$, T. hemprichii $(7,95 \%), H$. ovalis $(1,77 \%), C$. rotundata $(10.58 \%)$ dan $H$. pinifolia $(35.81 \%)$. $\mathrm{Tj}$. Tiram : E. acroides (41.51\%), T. hemprichii $(52,72 \%)$, $H$. ovalis $(0,61 \%)$ dan H. pinifolia (5.16\%). Lateri : : E. acroides (76.25\%) dan T. hemprichii (52,72\%). Passo : H. minor (100\%). Waiheru : E. acroides $(100 \%)$. Tawiri : H. ovalis $(46,45 \%)$ dan H. pinifolia $(53.55 \%)$

Hasil pengukuran parameter kualitas air Teluk Ambon bervariasi untuk setiap parameter. Suhu perairan lebih rendah dari suhu optimum. Salinitas perairan dan DO masih dalam bakumutu yang diperolehkan. Berdasarkan nilai pH maka perairan Teluk Ambon tergolong perairan tidak produktif. Kadar fosfat dan nitrat lebih tinggi dari bakumutu berdasarkan KMNLH 2004.

\section{Ucapan Terima Kasih}

Ucapan terima kasih disampaikan kepada Pusat Penelitian Laut Dalam - LIPI yang telah memberikan bantuan dalam bentuk anggaran penelitian yang bersumber dari DIPA.

\section{DAFTAR PUSTAKA}

Amelia, Y., Muskananfola, M.R dan Purnomo, P.W. 2014. Sebaran Struktur Sedimen, Bahan Organik, Nitrat dan Fosfat di Perairan Dasar Muara Morodemak. Diponegoro Journal of Maquares, Vol. 3 No. 4. Hal 208215.

Azkab, M. H. 1999. Pedoman Inventarisasi Lamun. Balitbang Biologi Laut, Puslitbang Oseanologi. Vol. XXIV No. 1. Hal 1-16.

Christianen MJA, van der Heide T, Bouma TJ, Roelofs JGM, van Katwijk MM, Lamers LPM. 2011. Limited Toxicity of NHx Pulses on an Early and Late Successional Tropical Seagrass Species: Interactions with $\mathrm{pH}$ and Light Level. Aquatic Toxicology. Vo.l 104. Pages 73-79.

Den Hartog, C. 1970. The Seagrass of the World. Amsterdam: North Holland.

Den Hartog, C. and Kuo, J. 2006. Taxonomy and biogeography of seagrasses. In: Larkum, A.W.D., Orth, R.J. and Duarte, C.M., Eds., Seagrasses. Biology, Ecology and Conservation, Springer, The Netherlands. Pages 124.

English S., C. Wilkinson, dan V, Baker. 1994. Survey Manual for Tropical Marine Resource (2nd Edition). Australian Institute of Marine Science. Australia. 41p.

Felisberto P, Jesus SM, Zabel F, Santos R, Silva J, Gobert S, Beer S, Björk M, Mazzuca S, Procaccini G, Runcie JW, Champenois W, Borges AV. 2015. Acoustic Monitoring of 02 Production of a Seagrass Meadow. Journal of Experimental Marine Biology and Ecology. Vol. 464. Pages 75-87.

Irawan, A. 2011. Komunitas lamun di Teluk Ambon. Perairan Maluku dan Sekitarnya. Hal 61-69.

Irawan A., NR Nganro. 2016. Distribution of Seagrasses in Inner Ambon Bay. Jurnal Ilmu dan Teknologi Kelautan Tropis, Vol. 8 No. 1. Hal $99-114$.

Kiswara, W. 2004. Kondisi Padang Lamun (Seagrass) di Teluk Banten 1998 - 2001. Pusat Penelitian dan Pengembangan Oseanologi. Lembaga Ilmu Pengetahuan Indonesia. Jakarta.

KMNLH. 2004. Pedoman Penetapan Baku Mutu Lingkungan. Kantor Menteri Negara Kependudukan dan Lingkungan Hidup 2004. Keputusan Menteri Negara 
Kependudukan dan Lingkunganh Hidup No. 51 Tahun 2004 tentang Baku Mutu Air Laut. Sekretariat Negara. Jakarta.

Kordi, K. M.G.H. 2011. Ekosistem Lamun (Seagrass). Jakarta: Rineka Cipta.

Menez, E.G., R.C. Phillips and HP. Calumpong. 1983. Seagrass from the Philippines. Smithsonian Cont. Mar. Sci., 21. Smithsonian. Press, Washington. $40 \mathrm{pp}$.

Papathanasiou V, Orfanidis S, Brown MT. 2015. IntraSpecific Responses of Cymodocea nodosa to MacroNutrient, Irradiance and Copper Exposure. Journal of Experimental Marine Biology and Ecology. Vol. 469. Pages 113-122.

Patty, S.I., Arfah, H. dan Abdul, M.S. 2015. Zat Hara (Fosfat, Nitrat), Oksigen Terlarut dan pH Kaitannya Dengan
Kesuburan Di Perairan Jikumerasa, Pulau Buru. Jurnal Pesisir dan Laut Tropis, Vol. 1 No. 1. Hal 43-50.

Short FT, Coles RG. (eds). 2003. Global Seagrass Research Methods. Amsterdam. Elsevier Science BV.

Tuapattinaya, P. M. J. 2014. Hubungan Faktor Fisik Kimia Lingkungan dengan Keanekaragaman lamun (seagrass) di Perairan Pantai Desa Suli. Jurnal Biologi Science \& Education. Biologi SKL, Vol. 3 No. 1. Hal 5467.

Tuwo, A. 2011. Pengelolaan Ekowisata Pesisir dan Laut. Brilian International. Surabaya. 412 hal.

Waycott M, Collier C, McMahon K, Ralph P, McKenzie L, Udy J, Grech A. 2007. Climate change and the Great Barrier Reef: a vulnerability assesment. Queensland. Department of Primary Industries and Fisheries. 